BMJ Open

Diabetes

Research

\& Care

\title{
Patient-specific factors associated with use of diabetes self-management education and support programs in Louisiana
}

\author{
Yilin Yoshida, ${ }^{1}$ Dongzhe Hong, ${ }^{2}$ Elizabeth Nauman, ${ }^{3}$ Eboni G Price-Haywood, ${ }^{4}$ \\ Alessandra N Bazzano, ${ }^{5}$ Charles Stoecker, ${ }^{2}$ Gang Hu (i) , ${ }^{6}$ Yun Shen, ${ }^{6,7}$ \\ Peter T Katzmarzyk, ${ }^{8}$ Vivian A Fonseca, ${ }^{1}$ Lizheng Shi $^{2}$
}

To cite: Yoshida Y, Hong D, Nauman $\mathrm{E}$, et al. Patientspecific factors associated with use of diabetes selfmanagement education and support programs in Louisiana. BMJ Open Diab Res Care 2021;9:e002136. doi:10.1136/ bmjdrc-2021-002136

Received 21 January 2021 Accepted 22 May 2021

Check for updates

\section{(C) Author(s) (or their} employer(s)) 2021. Re-use permitted under CC BY-NC. No commercial re-use. See rights and permissions. Published by BMJ.

For numbered affiliations see end of article.

Correspondence to Dr Yilin Yoshida; yyoshida1@tulane.edu

\section{ABSTRACT}

Introduction The prevalence of diabetes self-management education and support (DSME/S) use among patients with newly diagnosed type 2 diabetes mellitus (T2DM) and patients with insulin prescription has not been evaluated. It is also unclear what demographic, behavioral, and clinical factors associated with use of DSME/S.

Research design and methods This retrospective analysis was based on electronic health records from the Research Action for Health Network (2013-2019). Patients with newly diagnosed T2DM were identified as 35-94 year-olds diagnosed with $\mathrm{T} 2 \mathrm{DM} \geq 1$ year after the first recorded office visit. Patients with insulin were identified by the first insulin prescription records. DSME/S (Healthcare Common Procedure Coding System G0108 and G0109) codes that occurred from 2 months before the 'new diagnosis date' or first insulin prescription date through 1 year after were defined as use of DSME/S. Age-matched controls (non-users) were identified from the Electronic Health Records (EHR). The date of first DSME/S record was selected as the index date. Logistic regression was used to estimate the associations between patient factors and use of DSME/S.

Results The prevalence of DSME/S use was $6.5 \%$ (8909/137 629) among patients with newly diagnosed T2DM and $32.7 \%$ $(13,152 / 40,212)$ among patients with diabetes taking insulin. Multivariable analysis found that among patients with newly diagnosed T2DM, black and male patients were less likely to use DSME/S, while in patients with insulin, they were more likely to use the service compared with white and female counterparts, respectively. Among patients taking insulin, those with private insurance or self-pay status were significantly less likely, while those with Medicaid were more likely to use the service compared with their Medicare counterparts. A strong positive association was found between $\mathrm{HbA1c}$, obesity, and DSME/S use in both cohorts, while hypertension was negatively associated with DSME/S in both cohorts.

Conclusion We showed a low rate of DSME/S use in Louisiana, especially in patients with newly diagnosed T2DM. Our findings demonstrated heterogeneity in factors influencing DSME/S use between patients with newly diagnosed T2D and patients with insulin.

\section{BACKGROUND}

Type 2 diabetes mellitus (T2DM) is a manageable chronic condition that affects 34.2 million

\section{Significance of this study}

What is already known about this subject?

- Diabetes self-management education and support (DSME/S) is underused despite its efficacy in improving clinical, psychosocial, and behavioral outcomes demonstrated in trials and its service coverage by most health plans.

- Previous data suggest that there is a large gap between the recommended guideline and current practice, and that there is both an opportunity and a need to enhance rates of DSME/S participation among patients with diabetes.

What are the new findings?

- There was a low rate of DSME/S use in Louisiana, especially in patients with newly diagnosed type 2 diabetes mellitus (T2DM).

- Among patients with newly diagnosed T2DM, black and male patients were less likely to use DSME/S, while in patients taking insulin, they were more likely to use DSME/S compared with white and female counterparts, respectively.

- Insurance status appeared to play a role in using DSME/S among patients taking insulin. A strong positive association was found between $\mathrm{HbA1c}$, obesity, and DSME/S use in both cohorts, while hypertension was negatively associated with DSME/S in both cohorts.

How might these results change the focus of research or clinical practice?

- There were significant variations in factors associated with DSME/S use in two patient cohorts representing the initial and advanced stage of diabetes, respectively.

- Factors identified by this study can be used to reduce barriers to DSME/S access, coordinate existing services, and develop new methods of service delivery for patients with newly diagnosed T2DM or those undergoing insulin treatments.

people in the USA. ${ }^{1}$ Louisiana has the fourth highest diabetes prevalence in the nation ( $14 \%$ in the state vs $10.9 \%$ nationally in 2019 ), with the vast majority being T2DM. ${ }^{2}$ Diabetes 
self-management is a necessary component of diabetes care and plays an important role in glycemic outcome management and preventing or delaying diabetes-related complications when administered alongside medical care and management. ${ }^{3}$ Diabetes self-management education and support (DSME/S) is a comprehensive educational program designed to help people with diabetes navigate complex selfmanagement decisions and activities. ${ }^{4}$ The primary goals of DSME/S programs are to enhance diabetes self-care knowledge, skills training, learning how to overcome identified barriers, and to create self-efficacy. ${ }^{4}$ The American Diabetes Association (ADA) and the Association of Diabetes Care \& Education Specialists endorse the National Standards for DSME/S to promote quality education for this patient group. The ADA recommends that all individuals with diabetes receive DSME/S at diagnosis and as needed thereafter. ${ }^{4}$ The time immediately following diagnosis represents a critical window when patients are seeking information about their new condition and are likely to be overwhelmed by the many behavioral changes they are asked to adopt. ${ }^{5}$ The importance of DSME/S continues beyond the initial diagnosis. ${ }^{4}$ Receiving education at critical times during the disease progression, such as when new medication or treatment is needed, can help patients cope with new challenges, learn how to administer, and follow new self-care regimens, and appropriately adjust meal plans and physical activity levels to maximize health outcomes and quality of life. ${ }^{4}$

$\mathrm{DSME} / \mathrm{S}$ is underused despite its efficacy in improving clinical, psychosocial, and behavioral outcomes demonstrated in trials and its service coverage by most health plans. ${ }^{6-8}$ Reimbursement for DSME/S is available from the Centers for Medicare and Medicaid Services and many private payers. ${ }^{4}$ However, only $6.8 \%$ of individuals with newly diagnosed T2DM with private health insurance participated in DSME/S within 12 months of diagnosis. ${ }^{7}$ Only $4 \%$ of Medicare beneficiaries received DSME/S. ${ }^{8}$ Even among patients who attend DSME/S classes, attrition rates are often high. ${ }^{9}$ These data suggest there is a large gap between the recommended guideline and current practice, and that there is both an opportunity and a need to enhance rates of DSME/S participation among patients with diabetes. ${ }^{7}$

An increasing number of studies have examined barriers that contribute to the underuse and attrition of DSME/S. Known barriers include competing priorities, transportation difficulties, forgetfulness, apathy, low perceived seriousness of diabetes, and lack of accessible services. ${ }^{10-12}$ Many previous studies relied on selfreported data that did not necessarily consider the time of diagnosis of a patient, disease risk factors, and sociodemographic backgrounds. Given that patients may encounter different challenges at different stages of the disease, evaluating factors influencing DSME/S usage for the portion of newly diagnosed and those at disease and treatment transitions separately is necessary. The objectives of the study include (1) assessing the prevalence of receiving DSME/S among patients with newly diagnosed T2DM and patients who have undergone insulin treatments and (2) examining demographic, behavioral, and clinical factors associated with use of DSME/S in these two cohorts.

\section{METHODS}

Data source

This retrospective cross-sectional analysis is based on data from patients with T2DM in the LEAD cohort study (Louisiana Experiment Assessing Diabetes outcomes). The patient records were obtained through the Research Action for Health Network (REACHnet) from three partner health systems in Louisiana between January 1, 2013 and October 10, 2019.

\section{Sample and case definitions}

We first identified 35-94-year-old patients with T2DM. T2DM was defined by the Surveillance, Prevention, and Management of Diabetes Mellitus (SUPREME-DM) algorithms, ${ }^{13}$ that is meeting any of the following criteria: (1) one or more of the International Classification of Disease, Ninth Revision, Clinical Modification (ICD-9-CM) codes and Tenth Revision, Clinical Modification (ICD-10-CM) codes for T2DM associated with in-patient encounters; (2) two or more ICD codes associated with outpatient encounters on different days within 2 years; (3) combination of two or more of the following associated with outpatient encounters on different days within 2 years: (1) ICD codes; (2) fasting glucose level $\geq 126 \mathrm{mg} / \mathrm{dL}$; (3) 2-hour glucose level $\geq 200 \mathrm{mg} / \mathrm{dL}$; (4) random glucose $\geq 200 \mathrm{mg} / \mathrm{dL}$; (5) hemoglobin A1c (HbAlc) $\geq 6.5 \%$; and (6) prescription for an glucose-lowering medication. ${ }^{14} \mathrm{~A}$ total of 331242 patients with T2DM were identified.

New T2DM cases were defined as entry of T2DM diagnosis in the clinical record $\geq 1$ year after the first recorded office visit $(\mathrm{n}=137629)$. Patients taking insulin were identified by first insulin prescription records in the Electronic Health Records (EHR) ( $\mathrm{n}=40$ 212). DSME/S (Healthcare Common Procedure Coding System (HCPCS) codes G0108 and G0109) codes that occurred between 2 months before the 'new diagnosis date' or first insulin prescription date through 1 year after were defined as use of DSME/S service. After applying all criteria, a cohort of newly diagnosed cases included a total of $8909 \mathrm{DSME} / \mathrm{S}$ users and a cohort of patients taking insulin included a total of 3572 DSME/S users, respectively. Age-matched non-DSME/S users were also identified in the same study period. We adopted the gmatch macro in SAS that used the greedy matching algorithm with one non-user per user. $^{15}$ The date of first DSME/S record was selected as index date. For comparison, an index date was assigned as their matched DSME/S users.

\section{Measures}

The primary outcome was DSME/S use 2 months prior or within 1 year of the first diagnosed date or the first insulin prescription. Demographic variables included the following: age at diagnosis, sex, race, insurance type, and smoking status. Clinical or biomarkers included HbAlc, 
low-density lipoprotein (LDL), high-density lipoprotein (HDL), total cholesterol, triglycerides, blood pressure, and body mass index (BMI). These were average values of available lab or examination records in the study period. Medication use was measured by any prescription records of glucose-lowering, blood pressure-lowering, or lipid-lowering medications in the database.

\section{Analysis}

T-tests and $\chi^{2}$ tests were performed to compare differences between DSME/S and non-DSME/S groups $\geq 180$ days before the first recorded DSME/S (baseline) in the two cohorts, respectively. Multivariable logistic regression was used to estimate the independent effects of these baseline characteristics on DSME/S attendance. Covariates adjusted in multivariable model included age at diagnosis, sex, race, insurance type, smoking status, HbAlc, LDL, HDL, total cholesterol, triglycerides, blood pressure, BMI, glucose-lowering, blood pressure-lowering, and lipid-lowering medications. All analyses were performed using SAS V.9.2 (Cary, North Carolina, USA).

The study and analysis plan were approved by Tulane University Institutional Review Board (IRB number: 2019-1572). We used a limited dataset, as defined by HIPAA, abstracted from medical records that does not contain personally identifiable information except date of birth. The IRB granted a waiver of informed consent.

\section{RESULTS}

The prevalence of initial DSME/S use among patients within the first year of diagnosis was $6.5 \%(8909 / 137629)$ in the study period. In patients taking insulin, the prevalence of any DSME/S use (ie, initial or follow-up sessions) was 32.7\% (13 152/40 212). In insulin user group, 3572 patients attended $\mathrm{DSME} / \mathrm{S}$ for the first time. Compared with the age-matched non-DSME/S group, the DSME/S group had higher mean HbAlc (8.7 vs 6.9 and 9.4 vs 7.9 in newly diagnosed and patients with insulin cohort, respectively) and triglycerides (174.8 vs $137.8 \mathrm{mg} / \mathrm{dL}$ and $183.1 \mathrm{vs} 169.2 \mathrm{mg} / \mathrm{dL}$ in two cohorts, respectively), and higher prevalence of obesity (47.4 vs $31.3 \%$ and 46.2 vs $35.9 \%$ ) in both newly diagnosed patients and patients with insulin cohorts. In both cohorts, DSME/S group had fewer white patients (56.5 vs $65.3 \%$ and 50.4 vs $58 \%$, respectively), fewer current smokers (7.7 vs $15.9 \%$ and 8.6 vs $12.1 \%$, respectively), but more patients with Medicare or private insurance than their counterparts in the non-DSME/S group (94.4 vs $92 \%$ and 95.4 vs $89.3 \%$, respectively). In patients with insulin, more black patients were found in DSME/S compared with non-DSME/S group (48.1 vs $40.8 \%$, respectively). Fewer male patients were found in DSME/S than in non-DSME/S group (44.6 vs $49.6 \%$, respectively). In both cohorts, patients in DSME/S group had higher frequencies of taking any lipid-lowering drugs (51.9 vs $44.1 \%$ and 46.3 vs $38.2 \%$, respectively) or oral glucose-lowering drugs ( 84.5 vs $33.7 \%$ and 93 vs $69.5 \%$, respectively) but had less frequencies of taking any blood pressure-lowering drugs (71.9 vs $80.3 \%$ and 65.7 vs $68.2 \%$, respectively) (table 1 ).

Results from multivariable logistic regressions showed that among patients with newly diagnosed T2DM, black and other minority patients were less likely to use DSME/S compared with their white counterparts (OR $0.42,95 \%$ CI 0.35 to 0.51 and OR $0.1,0.05$ to 0.16 , in black and other minority group, respectively), and male patients were more likely to use DSME/S than their female counterparts $(1.63,1.34$ to 1.97). In contrast, among patients taking insulin, black were more likely to use DSME/S than their white counterparts (3.54, 3.01 to 4.16$)$, and male patients $(1.15,0.99$ to 1.32$)$ were less likely to use the service than their female counterparts. Among patients with insulin, those with private insurance or self-pay status were significantly less likely $(0.8,0.69$ to 0.93 and $0.33,0.16$ to 0.7 , in private insurance and self-pay group, respectively), while patients with Medicaid were more likely $(3.4,1.08$ to 10.68$)$ to use the service compared with their Medicare counterparts. Patients who were current or former smokers were less likely to use DSME/S in newly diagnosed patients $(0.43,0.41$ to 0.45 and $0.56,0.54$ to 0.58 in current and former smokers, respectively). Those with elevated HbAlc levels had more than a fivefold likelihood of receiving DSME/S compared with individuals with $\mathrm{HbAlc}$ within target range in the newly diagnosed T2DM cohort (5.4, 4.24 to 6.88$)$. A strong positive association was also found between obesity status (3.97, 3.11 to 5.07 and 3.23, 2.68 to 3.88 , in two cohorts, respectively) and DSME/S use in both cohorts; hypertension $(0.62,0.48$ to 0.81 and 0.69 , 0.56 to 0.84 in two cohorts, respectively), however, was negatively associated with DSME/S. In both cohorts, patients with any oral glucose-lowering medications were more likely to use DSME/S (1.78, 1.46 to 2.17 and 3.5, 3.04 to 4.03 in two cohorts, respectively), but patients with any blood pressurelowering drugs $(0.6,0.45$ to 0.8 and $1.32,1.14$ to 1.53 in two cohorts, respectively) were less likely to use DSME/S than those without the medications. Any use of lipid-lowering medications was negatively associated with use of DSME/S in newly diagnosed patients $(0.41,0.33$ to 0.5$)$ (table 2$)$.

\section{DISCUSSION}

Our results showed a low rate of DSME/S use in Louisiana, especially in patients with newly diagnosed T2DM. Our findings also demonstrated heterogeneity in patientspecific factors that influence use of DSME/S patients with among newly diagnosed T2DM and patients who have undergone insulin treatments. The patient-cohort stratification is important as people with T2DM face different challenges in self-management decisions and tasks at different stages of their disease. First, we found that black patients who had been prescribed insulin were more likely to use DSME/S than their white counterparts, which appears to be contradictory to the previous thinking that blacks were less likely to commit to self-management activities for their chronic conditions as a result of a variety of biopsychosocial and sociocultural factors. ${ }^{16}$ Some research suggested that those who initiated insulin treatments had 
Table 1 Demographic, behavioral, and clinical characteristics of patients with newly diagnosed T2DM and patients with insulin by DSME/S in Louisiana

\begin{tabular}{|c|c|c|c|c|c|c|}
\hline & \multicolumn{3}{|c|}{ New T2DM cohort ( $n=17$ 918) } & \multicolumn{3}{|c|}{ Patients with insulin cohort $(n=7144)$} \\
\hline & $\begin{array}{l}\text { DSME/S group } \\
(\mathrm{n}=8909)\end{array}$ & $\begin{array}{l}\text { Age-matched } \\
\text { non-DSME/S } \\
\text { group }(n=8909)\end{array}$ & $P$ value & $\begin{array}{l}\text { DSME/S group } \\
(\mathrm{n}=3572)\end{array}$ & $\begin{array}{l}\text { Age-matched } \\
\text { non-DSME/S } \\
\text { group }(n=3572)\end{array}$ & $P$ value \\
\hline Age (mean, SD) & 66 & 66 & 1.0 & 66 & 66 & 1.0 \\
\hline Race, \% & & & $<0.0001$ & & & $<0.0001$ \\
\hline White & 56.5 & 65.3 & & 50.4 & 58.0 & \\
\hline Black & 42.4 & 43.6 & & 48.1 & 40.8 & \\
\hline Others & 1.1 & 1.9 & & 1.5 & 1.2 & \\
\hline Males, \% & 45.1 & 45.2 & 0.91 & 44.6 & 49.6 & $<0.0001$ \\
\hline Insurance type, \% & & & $<0.0001$ & & & $<0.0001$ \\
\hline Private & 33.3 & 31.8 & & 32.5 & 25.9 & \\
\hline Medicare & 61.1 & 60.2 & & 61.9 & 63.4 & \\
\hline Medicaid & 2.1 & 3.7 & & 2.1 & 6.5 & \\
\hline Self-pay & 0.5 & 1.3 & & 0.4 & 1.5 & \\
\hline Unknown & 3.0 & 3.0 & & 3.1 & 2.7 & \\
\hline Tobacco use, \% & & & $<0.0001$ & & & $<0.0001$ \\
\hline Current smoker & 7.7 & 15.9 & & 8.6 & 12.1 & \\
\hline Never smoker & 82.4 & 70.3 & & 80.1 & 78.6 & \\
\hline Quit/former smoker & 9.9 & 13.8 & & 11.4 & 9.4 & \\
\hline \multicolumn{7}{|l|}{ Medications } \\
\hline Lipid-lowering drugs, \% & 51.9 & 44.1 & $<0.0001$ & 46.3 & 38.2 & $<0.0001$ \\
\hline $\begin{array}{l}\text { Oral glucose-lowering } \\
\text { drugs, } \%\end{array}$ & 84.5 & 33.7 & $<0.0001$ & 93.0 & 69.5 & $<0.0001$ \\
\hline $\begin{array}{l}\text { Blood pressure-lowering } \\
\text { drugs, \% }\end{array}$ & 71.9 & 80.3 & $<0.0001$ & 65.7 & 68.2 & 0.07 \\
\hline \multicolumn{7}{|l|}{ Clinical or biomarkers } \\
\hline HbA1c (\%), mean (SD) & $8.7(2.1)$ & $6.9(1.5)$ & $<0.0001$ & $9.4(2.3)$ & $7.9(2.0)$ & $<0.0001$ \\
\hline \multicolumn{7}{|l|}{$\begin{array}{l}\text { Blood pressure, } \mathrm{mm} \mathrm{Hg} \text {, } \\
\text { mean (SD) }\end{array}$} \\
\hline Systolic & $133.7(17.7)$ & $133.4(19.3)$ & 0.58 & $133.7(17.7)$ & $133.4(19.3)$ & 0.58 \\
\hline Diastolic & $76.5(10.7)$ & $76.3(11.3)$ & 0.43 & $76.5(10.7)$ & $76.3(10.3)$ & 0.42 \\
\hline $\begin{array}{l}\text { Total cholesterol, mg/dL, } \\
\text { mean }\end{array}$ & $178.3(47.9)$ & $176.8(42.3)$ & 0.22 & $178.0(56.4)$ & $168.8(53.0)$ & $<0.0001$ \\
\hline $\begin{array}{l}\text { LDL cholesterol, mg/dL, } \\
\text { mean (SD) }\end{array}$ & $102.3(37.2)$ & $102.6(34.5)$ & 0.74 & $100.0(40.7)$ & $93.4(38.3)$ & $<0.0001$ \\
\hline $\begin{array}{l}\mathrm{HDL} \text { cholesterol, mg/dL, } \\
\text { mean (SD) }\end{array}$ & $43.2(12.2)$ & $47.3(14.0)$ & $<0.0001$ & $43.2(13.3)$ & $43.2(14.0)$ & 0.99 \\
\hline $\begin{array}{l}\text { Triglycerides, mg/dL, } \\
\text { mean (SD) }\end{array}$ & $174.8(182.4)$ & $137.8(103.8)$ & $<0.0001$ & $183.1(220.4)$ & $169.2(231.6)$ & 0.11 \\
\hline Obesity (BMI >30), \% & 47.4 & 31.3 & $<0.0001$ & 46.2 & 35.9 & $<0.0001$ \\
\hline
\end{tabular}

BMI, body mass index; DSME/S, diabetes self-management education and support programs; HDL, high-density lipoprotein; LDL, lowdensity lipoprotein; T2DM, type 2 diabetes mellitus.

higher rates of self-care, such as following a healthier diet and engaging in self-monitoring of blood glucose, than those who did not use insulin. ${ }^{17} 18$ In race-stratified analyses, two studies have demonstrated that current black patients with insulin prescription who face a higher risk for diabetes-related morbidity and mortality are prone to engage in higher levels of diabetes-specific self-monitoring (blood glucose and foot care) than their white counterparts. ${ }^{19}$ This is consistent with our finding, indicating greater needs and perhaps, higher motivation to manage 
Table 2 Results from logistic regression for factors associated with DSME/S use among patients with newly diagnosed T2DM and patients with insulin in Louisiana

\begin{tabular}{|c|c|c|c|c|}
\hline & \multicolumn{2}{|c|}{ New T2DM cohort ( $n=17$ 918) } & \multicolumn{2}{|c|}{ Patients with insulin cohort $(n=7144)$} \\
\hline & Crude OR (95\% CI) & Adjusted OR (95\% CI) & Crude OR $(95 \% \mathrm{Cl})$ & Adjusted OR (95\% Cl) \\
\hline \multicolumn{5}{|l|}{ Race } \\
\hline White (ref.) & 1 & 1 & & \\
\hline Black & 0.99 (0.95 to 1.03$)$ & $0.42(0.35 \text { to } 0.51)^{\star}$ & $1.35(1.32 \text { to } 1.39)^{\star \star}$ & $3.54(3.01 \text { to } 4.16)^{\star \star}$ \\
\hline Others & $0.71(0.61 \text { to } 0.84)^{\star *}$ & $0.10(0.05 \text { to } 0.16)^{\star \star}$ & $1.44(1.31 \text { to } 1.59)^{\star *}$ & $0.13(0.10 \text { to } 0.16)^{\star \star}$ \\
\hline \multicolumn{5}{|l|}{ Sex } \\
\hline Female (ref.) & 1 & 1 & 1 & 1 \\
\hline Male & 0.99 (0.95 to 1.02$)$ & $1.63(1.34 \text { to } 1.97)^{\star \star}$ & $0.76(0.74 \text { to } 0.77)^{\star \star}$ & 1.15 (0.99 to 1.32$)$ \\
\hline \multicolumn{5}{|l|}{ Insurance } \\
\hline Medicare (ref.) & 1 & 1 & 1 & 1 \\
\hline Medicaid & $0.59(0.51 \text { to } 0.58)^{\star \star}$ & 1.97 (0.63 to 6.22$)$ & $0.33(0.31 \text { to } 0.35)^{\star \star}$ & $3.40(1.08 \text { to } 10.68)^{* *}$ \\
\hline Private & $1.03(1.00 \text { to } 1.06)^{\star \star}$ & 1.09 (0.89 to 1.33$)$ & $1.28(1.25 \text { to } 1.32)^{\star *}$ & $0.80(0.69 \text { to } 0.93)^{\star \star}$ \\
\hline Self-pay and unknown & $0.39(0.34 \text { to } 0.44)^{\star *}$ & $2.62(0.36$ to 18.96$)$ & $0.25(0.21 \text { to } 0.29)^{\star \star}$ & $0.33(0.16 \text { to } 0.70)^{\star \star}$ \\
\hline \multicolumn{5}{|l|}{ Smoking } \\
\hline Never (ref.) & 1 & 1 & 1 & 1 \\
\hline Current & $0.43(0.41 \text { to } 0.45)^{\star \star}$ & $0.32(0.23 \text { to } 0.44)^{\star \star}$ & $0.70(0.61 \text { to } 0.80)^{\star \star}$ & 1.34 (0.95 to 1.89$)$ \\
\hline Former & $0.56(0.54 \text { to } 0.58)^{\star \star}$ & $0.34(0.26 \text { to } 0.43)^{\star \star}$ & $1.20(1.03 \text { to } 1.40)^{\star \star}$ & $1.29(1.00 \text { to } 1.63)^{\star}$ \\
\hline \multicolumn{5}{|l|}{ Medications } \\
\hline \multicolumn{5}{|l|}{ Lipid-lowering drugs } \\
\hline No, ref. & 1 & 1 & 1 & 1 \\
\hline Yes & $1.39(1.35 \text { to } 1.43)^{\star \star}$ & $0.41(0.33 \text { to } 0.50)^{\star *}$ & $1.91(1.86 \text { to } 1.96)^{\star \star}$ & 0.97 (0.84 to 1.11$)$ \\
\hline \multicolumn{5}{|c|}{ Oral glucose-lowering drugs } \\
\hline No, ref. & 1 & 1 & 1 & 1 \\
\hline Yes & $11.56(11.20 \text { to } 11.93)^{\star \star}$ & $1.78(1.46 \text { to } 2.17)^{\star}$ & $4.96(4.82 \text { to } 5.11)^{\star \star}$ & $3.50(3.04 \text { to } 4.03)^{\star \star}$ \\
\hline \multicolumn{5}{|c|}{ Blood pressure-lowering drugs } \\
\hline No, ref. & 1 & 1 & 1 & 1 \\
\hline Yes & $0.65(0.63 \text { to } 0.67)^{\star \star}$ & $0.60(0.45 \text { to } 0.80)^{*}$ & $0.79(0.77 \text { to } 0.82)^{\star *}$ & $1.32(1.14 \text { to } 1.53)^{\star}$ \\
\hline \multicolumn{5}{|l|}{ Clinical risks } \\
\hline \multicolumn{5}{|l|}{ Elevated HbA1c (>7\%) } \\
\hline No, ref & 1 & 1 & 1 & 1 \\
\hline Yes & $8.95(8.61 \text { to } 9.31)^{\star \star}$ & $5.40(4.24 \text { to } 6.88)^{\star \star}$ & $5.11(4.96 \text { to } 5.27)^{\star \star}$ & $1.34(1.14 \text { to } 1.53)^{\star \star}$ \\
\hline \multicolumn{5}{|c|}{ Elevated blood pressure $(\mathrm{SBP}>130 / \mathrm{DBP}>80 \mathrm{~mm} \mathrm{Hg})$} \\
\hline No, ref & 1 & 1 & 1 & 1 \\
\hline Yes & $0.28(0.27 \text { to } 0.29)^{\star \star}$ & $0.62(0.48 \text { to } 0.81)^{\star \star}$ & $0.40(0.37 \text { to } 0.43)^{\star \star}$ & $0.69(0.56 \text { to } 0.84)^{\star \star}$ \\
\hline \multicolumn{5}{|c|}{ Elevated total cholesterol (>200 mg/dL) } \\
\hline No, ref. & 1 & 1 & 1 & 1 \\
\hline Yes & 1.04 (0.99 to 1.08$)$ & 1.25 (0.98 to 1.58$)$ & $1.29(1.24 \text { to } 1.34)^{\star *}$ & $0.96(0.80$ to 1.16$)$ \\
\hline \multicolumn{5}{|l|}{ Obesity (BMI >30) } \\
\hline No, ref. & 1 & 1 & 1 & 1 \\
\hline Yes & $2.22(2.17 \text { to } 2.28)^{\star \star}$ & $3.97(3.11 \text { to } 5.07)^{\star \star}$ & $1.88(1.74 \text { to } 2.03)^{\star \star}$ & $3.23(2.68 \text { to } 3.88)^{\star \star}$ \\
\hline
\end{tabular}

${ }^{*}<0.05 ;{ }^{* *}<0.0001$. Adjusted model included all variables listed in the table.

$\mathrm{BMI}$, body mass index; DBP, distolic blood pressure; DSME/S, diabetes self-management education and support programs; SBP, systolic blood pressure; T2DM, type 2 diabetes mellitus. 
the health conditions among black patients with insulin prescription.

Additionally, we found an interesting sex difference in receiving DSME/S, especially in the newly diagnosed T2DM patient cohort. It is often thought that women are prone to use socially interactive resources, like education classes and support groups, whereas men rely more on self-directed learning. ${ }^{21-23}$ Yet, previous research regarding the sex difference in receiving DSME/S did not show women had a significantly higher rates in participating in the service. ${ }^{17} 24$ Our finding showed that among patients with newly diagnosed T2DM, men were significantly more likely to use DSME/S compared with women. There were data showing men expressed significantly greater need for information on primary prevention issues and unhealthy health practices, such as smoking. ${ }^{25}$ Data from the Health and Retirement Study also indicated that women were less likely to use preventive care including influenza shot or cholesterol screening, to have hospital stays, and to have fewer physician visits than men with similar health profiles. ${ }^{26}$ Compared with men, women with healthcare problems may be more isolated or have more caregiving responsibility, limiting their ability to obtain medical services. ${ }^{26}{ }^{27}$ Additionally, women are less likely than men to be insured through their own job and more likely to be covered as a dependent, and more often cite financial and transportation barriers to accessing healthcare and treatment. ${ }^{28}$ All these factors are likely to explain the sex difference in receiving DSME/s seen in our study.

Further, we identified a differential role of smoking status in receiving DSME/S by patient cohort. Consistent with previous findings, our data showed that smokers were significantly less likely to use DSME/S in patients with newly diagnosed T2DM, ${ }^{10} 2329$ while in patients with more advanced diabetes (ie, those with insulin), smoking, especially former smoking status, was positively associated with use of DSME/S. This scenario may be explained by a 'healthy smoker' effect (where sick smokers selectively quit smoking and seeking healthcare and advice at greater rates than healthy smokers).$^{30}$ Several studies found smokers were less likely to use primary care or preventive services compared with non-smokers. This may be due to an optimistic bias in relation to smoking, such that smokers tend to see the risks of smoking as lower for themselves than for others. ${ }^{30-32}$ Fewer smokers than ex-smokers accept that smoking causes disease, and smokers also maintain beliefs that exempt them from personalizing widespread acceptance that smoking harms health. ${ }^{33}$ Such attitudes might translate into denial of other health risks (such as diabetes related complications) and delay in seeking disease management skills. On the contrary, 'sick smokers' such that who have longer diabetes history (ie, those with insulin) tend to 'look after themselves' by seeking more healthcare and services.

Uninsured status has been identified as a barrier to accessing and attending health education sessions. ${ }^{34}$ However, there are limited data examining payer type and DSME/S use. ${ }^{71029}$ In our study, we found among patients with insulin, those with self-pay or private insurance status were significantly less likely to attend the service compared with Medicare beneficiaries. Some patients with diabetes may already struggle with the equipment and supplies necessary to manage their diabetes; the added cost of paying for DSME/S out of pocket, either because the patient does not have insurance or due to insurance cost-sharing requirements, could be a barrier to participation. ${ }^{71029}$ Additionally, we found patients with insulin with Medicaid were more likely to use the service compared with their Medicare counterparts. Relative to the Medicare group, Medicaid patients are generally younger, have fewer comorbidities, ${ }^{35}$ and do not need to obtain a referral from the healthcare professional treating their diabetes to receive the service coverage. ${ }^{36}$ All these factors may contribute to the higher likelihood of DSME/S in Medicaid relative to Medicare patients that found in this study.

Among clinical factors, elevated HbAlc at baseline was significantly associated with use of DSME/S, especially in newly diagnosed patients. In a similar vein, patients with any glucose-lowering medication also had significantly higher odds of DSME/S use, which appears to reflect the same pattern that people with high demand on glycemic outcome management are more likely to take advantage of DSME/S. Additionally, in both newly diagnosed patients and those with insulin, hypertension was negatively associated with use of DSMES/S, which is in line with previous research.$^{37}$ Compared with elevated HbA1c, hypertension did not appear to motivate patients to seek self-management skills in our study. Reasons for the lower DSME/S use among hypertensive patients with T2DM are not clear but may be due to the low awareness of severe consequences of hypertension in diabetes and the importance of blood pressure management. ${ }^{38-40}$ Findings from clinic-based and population-based surveys have shown that only $13 \%-40 \%$ of patients with diabetes achieved optimal blood pressure targets, ${ }^{38-40}$ and one study found fewer than half of patients with hypertension were aware of the importance of blood pressure management. ${ }^{41}$ One important component of DSME/S is to educate patients with health monitoring, including blood pressure monitoring. Our findings further indicate the needs to promote DSME/S among patients with T2DM, especially among those with uncontrolled blood pressure. Moreover, we found obesity was associated with more than threefold higher odds of DSME/S use in both patient cohorts. More than half of adults with diabetes are obese, ${ }^{42}$ and the first few months postdiagnosis is a key window during which patients with diabetes may actively seek and apply weight-loss interventions. ${ }^{43}$ What makes weight control challenging in T2DM is that many pharmacological agents including insulin directly contribute to weight gain through their glucose-lowering mechanisms. ${ }^{44}$ Also, patients engaging in lifestyle interventions who initially lost weight may encounter a plateau in weight loss, generally followed by a weight regain. ${ }^{46}$ Weight management is a long-term task for patients with T2DM, which is a plausible reason for the 
higher likelihood of DSME/S use among obese patients in both our patient cohorts.

\section{Limitations and strengths}

This is the first study to examine the demographic, behavioral, and clinical factors that are associated with DSME/S use in Louisiana, where the T2DM rate is persistently higher than the national level and diabetes education is critically needed. ${ }^{2}$ There are several limitations to be acknowledged. First, this is a cross-sectional analysis which limits the ability to make temporal or causal inferences. Second, we used the HCPCS codes to identify use of DSME/S, which is not equivalent to the actual completion or commitment of DSME/S, and those without HCPCS codes (ie, non-users) possibly had been referred to but did not attend the service. However, HCPCS codes are the best proxy available to identify those with or without exposure to DSME/S. Additionally, the SUPREME-DM algorisms cannot distinguish members with type 1 diabetes (T1DM) and T2DM with a high level of precision. However, SUPREME-DM is the gold standard algorisms to identify non-T1DM adults, that is, for adults with T2DM and DM of uncertain and rare types. ${ }^{47}$ Further, medication records used in the analysis were based on prescription records from providers. Dispensing data were not available for this analysis. We also acknowledged that smoking status/ tobacco use in EHR is notoriously inaccurate or not routinely updated. Since the accuracy of smoking status could not be confirmed for this observational analysis, we caution the interpretation of the relationship between smoking status and DSME/S use. Moreover, the association between 'Other race/ethnicity', 'Medicaid' or 'Private insurance', and use of the DSME/S should also be interpreted with caution. These covariate categories are small in counts. In multivariable logistic regression, the logit coefficients of these variables may suffer from small sample bias, which potentially leads to overestimation or underestimation. With these limitations being noted, the patient-specific factors identified from the study may be more modifiable in enhancing DSME/S use compared with removing barriers in clinics, healthcare system or environment. Last, we did not include healthcare providers' characteristics or healthcare system barriers that also influence patients' access and utilization of DSME/S. Additionally, the study assessed a large population of patients in routine clinical care in Louisiana; the results are therefore more generalizable than those from single-centered clinical trials with selective inclusion criteria.

\section{CONCLUSION}

Our study demonstrated a low rate of DSME/S in Louisiana. We also uncovered significant variations in factors associated with DSME/S use in two patient cohorts representing the initial and advanced stage of diabetes, respectively. Knowledge about the patient-specific barriers to receiving DSME/S is the first step in improving DSME/S uptake. Factors identified by this study can be used to reduce barriers to DSME/S access, coordinate existing services, and develop new methods of service delivery for patients with newly diagnosed T2DM or those undergoing insulin treatments.

Author affiliations

${ }^{1}$ Section of Endocrinology and Metabolism, Department of Medicine, Tulane University School of Medicine, New Orleans, Louisiana, USA

${ }^{2}$ Department of Global Health Management and Policy, Tulane University School of Public Health and Tropical Medicine, New Orleans, Louisiana, USA

${ }^{3}$ Louisiana Public Health Institute, New Orleans, Louisiana, USA

${ }^{4}$ Ochsner Center for Outcomes and Health Services Research, Ochsner Health

System, New Orleans, Louisiana, USA

${ }^{5}$ Department of Global Community Health and Behavioral Sciences, Tulane University School of Public Health and Tropical Medicine, New Orleans, Louisiana, USA

${ }^{6}$ Chronic Disease Epidemiology, Pennington Biomedical Research Center, Baton

Rouge, Louisiana, USA

${ }^{7}$ Shanghai Jiao Tong University, Shanghai, China

${ }^{8}$ Physical Activity and Obesity Epidemiology, Pennington Biomedical Research Center, Baton Rouge, Louisiana, USA

Acknowledgements The LEAD Study (Louisiana Experiment Assessing Diabetes outcomes) acknowledge the contributions of our partners. The success of this study depended on their ongoing support and expertise. These partners include Ochsner Health System and the Ochsner Patient Research Advisory Board; Tulane Medical Center; Louisiana State University (LSU); Research Action for Health Network (REACHnet, a PCORnet CDRN) and their multistakeholder Diabetes Advisory Groups; Pennington Biomedical Research Center; Blue Cross and Blue Shield of Louisiana; Peoples Health; and our patient and community partners Patricia Dominick, Catherine Glover, and Peggy Malone. The authors acknowledge the participation of REACHnet partner health systems, Ochsner Health, Tulane Medical Center, and University Medical Center, in this project.

Contributors YY designed and performed the analysis and wrote the first draft of the manuscript. DH and YS provided analytical support. All authors contributed to critically reviewing the paper and approved the final version.

Funding This work was supported by a Patient-Centered Outcomes Research (PCORI) cooperative agreement (NEN-1508-32257) as part of Natural Experiments for Translation in Diabetes 2.0 (NEXT-D2) and was conducted in partnership with Research Action for Health Network (REACHnet), funded by the Patient Centered Outcomes Research Institute (RI-CRN-2020-008). REACHnet is a partner network in PCORnet, the National Patient-Centered Clinical Research Network, which was developed with funding from PCORI. The work related to this manuscript occurred prior to EGP-H's appointment to the PCORI Board of Governors. YY was partly supported by a grant (NIH K12HD043451) from the Eunice Kennedy Shriver National Institute of Child Health \& Human Development of the Building Interdisciplinary Research Careers in Women's Health (BIRCWH) Scholar. GH, YS and PTK were partly supported by a grant from the National Institute of General Medical Sciences (U54GM104940) of the National Institutes of Health. All coauthors are also partly supported by a grant (CDC/NIDDK 1U18DP006523).

Disclaimer The content of this manuscript is solely the responsibility of the author(s) and does not necessarily represent the views of other organizations participating in, collaborating with, or funding REACHnet or PCORnet, or of PCORI, its Board of Governors, or Methodology Committee.

Competing interests None declared.

Patient consent for publication Not required.

Ethics approval The study and analysis plan were approved by Tulane University Institutional Review Board (IRB number: 2019-1572).

Provenance and peer review Not commissioned; externally peer reviewed.

Data availability statement The data are electronic medical records that are not publicly available. They may contain information that could compromise the privacy of the included patients.

Open access This is an open access article distributed in accordance with the Creative Commons Attribution Non Commercial (CC BY-NC 4.0) license, which permits others to distribute, remix, adapt, build upon this work non-commercially, and license their derivative works on different terms, provided the original work is properly cited, appropriate credit is given, any changes made indicated, and the use is non-commercial. See: http://creativecommons.org/licenses/by-nc/4.0/. 
ORCID iD

Gang Hu http://orcid.org/0000-0002-6172-8017

\section{REFERENCES}

1 Statistics about diabetes [Internet], 2019. Available: https://www. diabetes.org/resources/statistics/statistics-about-diabetes

2 Diabetes Rate by State, 2019 [Internet], 2019. Available: https://www. americashealthrankings.org/explore/annual/measure/Diabetes/state/LA

3 Beck J, Greenwood DA, Blanton L, et al. 2017 national standards for diabetes self-management education and support. Diabetes Educ 2017;43:449-64.

4 Powers MA, Bardsley JK, Cypress M, et al. Diabetes Selfmanagement Education and Support in Adults With Type 2 Diabetes: A Consensus Report of the American Diabetes Association, the Association of Diabetes Care \& Education Specialists, the Academy of Nutrition and Dietetics, the American Academy of Family Physicians, the American Academy of PAs, the American Association of Nurse Practitioners, and the American Pharmacists Association. Diabetes Care 2020;43:1636-49.

5 Graziani C, Rosenthal MP, Diamond JJ. Diabetes education program use and patient-perceived barriers to attendance. Fam Med 1999;31:358-63.

6 Powers MA, Bardsley J, Cypress M, et al. Diabetes self-management education and support in type 2 diabetes: a joint position statement of the American diabetes association, the American association of diabetes educators, and the Academy of nutrition and dietetics. Clin Diabetes 2016;34:70-80.

7 Li R, Shrestha SS, Lipman R, et al. Diabetes self-management education and training among privately insured persons with newly diagnosed diabetes--United States, 2011-2012. MMWR Morb Mortal Wkly Rep 2014;63:1045-9.

8 Duncan I, Birkmeyer C, Coughlin S, et al. Assessing the value of diabetes education. Diabetes Educ 2009;35:752-60.

9 Nguyen AL, Sepulveda E, Angulo M. "It Feels Good to Know That Someone Cares". Hisp Health Care Int 2017;15:52-7.

10 Benoit SR, Ji M, Fleming R, et al. Predictors of dropouts from a San Diego diabetes program: a case control study. Prev Chronic Dis 2004;1:A10.

11 Gucciardi E, Demelo M, Offenheim A, et al. Factors contributing to attrition behavior in diabetes self-management programs: a mixed method approach. BMC Health Serv Res 2008;8:33.

12 Peyrot M, Rubin RR. Access to diabetes self-management education. Diabetes Educ 2008;34:90-7.

13 Pathak RD, Schroeder EB, Seaquist ER, et al. Severe hypoglycemia requiring medical intervention in a large cohort of adults with diabetes receiving care in U.S. integrated health care delivery systems: 2005-2011. Diabetes Care 2016;39:363-70.

14 Nichols GA, Desai J, Elston Lafata J, et al. Construction of a multisite Datalink using electronic health records for the identification, surveillance, prevention, and management of diabetes mellitus: the SUPREME-DM project. Prev Chronic Dis 2012;9:E110.

15 Erik Bergstralh JK. gmatch Mayo clinic division of biomedical statistics and informatics 2007.

16 Mingo CA, Smith ML, Ahn S, et al. Chronic disease self-management education (CDSME) program delivery and attendance among UrbanDwelling African Americans. Front Public Health 2014;2:174.

17 Beckles GL, Engelgau MM, Narayan KM, et al. Population-Based assessment of the level of care among adults with diabetes in the U.S. Diabetes Care 1998;21:1432-8.

$18 \mathrm{Xu}$ Y, Pan W, Liu H. Self-Management practices of Chinese Americans with type 2 diabetes. Nurs Health Sci 2010;12:228-34.

19 Johnson PJ, Ghildayal N, Rockwood T, et al. Differences in diabetes self-care activities by race/ethnicity and insulin use. Diabetes Educ 2014;40:767-77.

20 Nwasuruba C, Osuagwu C, Bae S, et al. Racial differences in diabetes self-management and quality of care in Texas. $J$ Diabetes Complications 2009;23:112-8.

21 Mathew R, Gucciardi E, De Melo M, et al. Self-Management experiences among men and women with type 2 diabetes mellitus: a qualitative analysis. BMC Fam Pract 2012;13:122.

22 Ray-Mazumder S. Role of gender, insurance status and culture in attitudes and health behavior in a US Chinese student population. Ethn Health 2001;6:197-209.

23 Winkley K, Stahl D, Chamley M, et al. Low attendance at structured education for people with newly diagnosed type 2 diabetes: general practice characteristics and individual patient factors predict uptake. Patient Educ Couns 2016:99:101-7.
24 Bzowyckyj AS, Aquilante CL, Cheng A-L, et al. Leveraging the electronic medical record to identify predictors of Nonattendance to a diabetes self-management education and support program. Diabetes Educ 2019;45:544-52.

25 Al-Khashan HI, Almulla NA, Galil SAA, et al. Gender differences in health education needs and preferences of Saudis attending Riyadh military hospital in the Kingdom of Saudi Arabia. J Family Community Med 2012;19:172-7.

26 Cameron KA, Song J, Manheim LM, et al. Gender disparities in health and healthcare use among older adults. $J$ Womens Health 2010;19:1643-50.

27 Bierman AS, Clancy CM. Making capitated Medicare work for women: policy and research challenges. Womens Health Issues 2000;10:59-69.

28 Bartz D, Chitnis T, Kaiser UB, et al. Clinical advances in sex- and Gender-Informed medicine to improve the health of all: a review. JAMA Intern Med 2020;180:574-83.

29 Gucciardi E, DeMelo M, Booth G, et al. Individual and contextual factors associated with follow-up use of diabetes self-management education programmes: a multisite prospective analysis. Diabet Med 2009;26:510-7.

30 Jorm LR, Shepherd LC, Rogers KD, et al. Smoking and use of primary care services: findings from a population-based cohort study linked with administrative claims data. BMC Health Serv Res 2012;12:263.

31 Arnett JJ. Optimistic bias in adolescent and adult smokers and nonsmokers. Addict Behav 2000;25:625-32.

32 Wacker M, Holle R, Heinrich J, et al. The association of smoking status with healthcare utilisation, productivity loss and resulting costs: results from the population-based KorA F4 study. BMC Health Serv Res 2013;13:278.

33 Chapman S, Wong WL, Smith W. Self-exempting beliefs about smoking and health: differences between smokers and ex-smokers. Am J Public Health 1993;83:215-9.

34 Villarroel MA, Cohen RA. Health insurance continuity and health care access and utilization, 2014. NCHS Data Brief 2016;249:1-8.

35 Garfield SS, Xenakis JJ, Bastian A, et al. Experiences of people with diabetes by payer type: an analysis of the Roper diabetes data set. Diabetes Ther 2015;6:113-25.

36 A Key Tool in Health Care: Diabetes Self-Mangement Education and Training [Internet], 2017. Available: https://www.changelabsolutions. $\mathrm{org} / \mathrm{sites} /$ default/files/Louisiana_DSMET_FINAL.pdf

37 Azam LS, Jackson TA, Knudson PE, et al. Use of secondary clinica data for research related to diabetes self-management education. Res Social Adm Pharm 2017;13:494-502.

38 Beaton SJ, Nag SS, Gunter MJ, et al. Adequacy of glycemic, lipid, and blood pressure management for patients with diabetes in a managed care setting. Diabetes Care 2004:27:694-8.

39 Eliasson B, Cederholm J, Nilsson P, et al. Steering Committee of the Swedish national diabetes $R$. the gap between guidelines and reality: type 2 diabetes in a national diabetes register 1996-2003. Diabet Med 2005;22:1420-6.

40 Yoshida Y, Fonseca VA. Diabetes control in Asian Americans - Disparities and the role of acculturation. Prim Care Diabetes 2021;15:187-190.

41 Wong N, Wang SS, Lamoureux E, et al. Blood pressure control and awareness among patients with diabetes and hypertension attending a tertiary ophthalmic clinic. Diabet Med 2009;26:34-9.

42 Centers for Disease Control and Prevention (CDC). Prevalence of overweight and obesity among adults with diagnosed diabetes-United States, 1988-1994 and 1999-2002. MMWR Morb Mortal Wkly Rep 2004;53:1066-8.

43 Feldstein AC, Nichols GA, Smith DH, et al. Weight change in diabetes and glycemic and blood pressure control. Diabetes Care 2008;31:1960-5.

44 van Dieren S, Czernichow S, Chalmers J, et al. Weight changes and their predictors amongst 11140 patients with type 2 diabetes in the advance trial. Diabetes Obes Metab 2012;14:464-9.

45 Van Gaal L, Scheen A. Weight management in type 2 diabetes: current and emerging approaches to treatment. Diabetes Care 2015;38:1161-72.

46 Pi-Sunyer FX. Weight loss in type 2 diabetic patients. Diabetes Care 2005;28:1526-7.

47 Raebelet al. Validating type 1 and type 2 diabetes mellitus in the MINISENTINEL distributed database using the surveillance, prevention, and management of diabetes mellitus (SUPREMEDM) Datalink. The Mini-Sentinel Coordinating Center 2016. 